\title{
Role of herbs in root canal irrigation-A review
}

\author{
Pratishta Jain ${ }^{1}$, Manish Ranjan ${ }^{2}$ \\ ' (Final year BDS, Saveetha dental college, India) \\ ${ }^{2}$ (Department of Conservative dentistry \& Endodontics, Saveetha dental college, India)
}

\begin{abstract}
One of the major objectives of a root canal treatment is to disinfect the root canal system. Irrigation is carried out to reduce the number of bacteria in the root canals. For this purpose, a wide variety of synthetic drugs are available today but due to the ineffectiveness, safety concerns and side effects of these synthetic drugs, the herbal alternatives for endodontic irrigants might be advantageous. Herbal alternatives are popular mainly due to their easy availability, cost effectiveness, increased shelf life and low toxicity. Thus this review aims at providing a comprehensive overview of the various herbal endodontic irrigants and their efficacy in carrying out root canal irrigation.
\end{abstract}

Keywords: chlorhexidine, herbs, irrigation, root canal, sodium hypochlorite

\section{Introduction}

The main aim of an endodontic treatment is to remove the diseased tissue, eliminate bacteria from the root canal system and prevent its recontamination. [1] Irrigation is carried out to reduce the number of bacteria in the root canal system and to control the periapical disease. [2]

A wide variety of synthetic antimicrobial agents have been used over the years as endodontic irrigants. Because of the increased antibiotic resistance to these antimicrobial agents, toxic and harmful side effects of few common antibacterial agents, there is a need for alternative agents which are affordable, non-toxic and effective. It has been found that natural plant extracts could be used as effective endodontic irrigants. [3] The ideal properties of a root canal irrigant are: it should be systemically nontoxic, should not harm the periodontal tissues, should not cause an anaphylactic reaction, should possess a broad antimicrobial spectrum, should be capable of dissolving necrotic pulp tissue, inactivating endotoxins, and either preventing the formation of a smear layer or dissolving it once it has formed. [4] Sodium hypochlorite $(\mathrm{NaOCl})$ is one of the most widely used endodontic irrigant because of its ability to destroy a broad spectrum of microbes but it has some undesirable characteristics such as tissue toxicity, allergic potential, and disagreeable taste and inability to remove the smear layer. $[5,6,7]$ For this reason Ethylenediaminetetraacetic acid (EDTA) was used, which effectively demineralises the smear layer [8] but has to be used along with $\mathrm{NaOCl}$ to remove the organic part [9] and does not have disinfective ability. [10] Chlorhexidine is another commonly used antimicrobial agent which is being used to irrigate the canals due to its wide spectrum antimicrobial activity, biocompatibility and ability to disinfect the infected root canals. However it does not have tissue dissolving capabilities [11] and also has some undesirable effects as it may discolour the teeth, [12] may lead to dryness of the oral cavity and may even cause burning sensation of the mouth.

To overcome the side effects of the above agents and to meet the requirements of an ideal irrigant, a new agent was introduced known as MTAD. It is an aqueous solution of 3\% doxycycline, a broad-spectrum antibiotic; $4.2 \%$ citric acid, a demineralizing agent; and $0.5 \%$ polysorbate 80 detergent (Tween 80 ). It also has some disadvantages such as high cost, reduced shelf life, less compatibility dental pulp cells. [14]

Herbal or natural products have also become more popular today due to their high antimicrobial activity, biocompatibility, anti-inflammatory and anti-oxidant properties. [15] A wide variety herbal products have been used in the past in medicine. Thus the aim of this review is to enlist and describe the various herbal alternatives available today for use as effective endodontic irrigants.

\subsection{Curcuma longa (Turmeric):}

\section{Herbal Endodontic Irrigants}

Curcumin, a member of a ginger family possesses anti inflammatory [16], anti oxidant [17], anti microbial [18] and anti cancer activity [19]. In an in vitro study conducted by Prasanna Neelakantan, it has been shown that curcumin has significant anti bacterial activity against E.faecalis and can be used as an alternative to sodium hypochlorite for root canal irrigation. Thus this herb can be used especially in endodontics for root canal failure cases. [20] 


\subsection{Propolis:}

Propolis, a natural antibiotic is a resinous substance that honey bees collect from trees of poplars and conifers. It possesses anti bacterial activities against streptococcus sobrinus and streptococcus mutans. [21] It also possesses good anti oxidant [22] and anti inflammatory activities [23]. It has been used as a pulp capping agent [24], cariostatic agent [25], as a mouth rinse [26] and in the treatment of periodontitis [27]. Ethanolic extract of propolis can promote bone regeneration and induce formation of hard tissue bridge in pulpotomies or pulp capping. In a study conducted by Al-Qathami and Al-Madi,the anti microbial efficacy of propolis, sodium hypochlorite and saline as endodontic irrigants was compared and it was found that propolis showed anti microbial activity equal to that of sodium hypochlorite. [28]

\subsection{Acacia nilotica (Babool):}

Acacia nilotica also known as the gum Arabic tree, possesses good anti microbial[29], anti oxidant [30], anti fungal [31], anti viral [32] and antibiotic activity [33]. It has been shown by Rosina Khan et al that this tree possesses anti bacterial activity against streptococcus mutans and E.faecalis. [34] In another study by Dhanya Kumar et al, extracts of liquorice, clove, cinnamon, babool were investigated for their anti microbial activity. It was shown that babool at a concentration of 50\% had the highest activity against E.faecalis. [35]

\subsection{Azadirachta indica (Neem):}

Neem's anti viral [36], anti fungal [37], anti bacterial [39] and anti carcinogenic activity [38] makes it a potential agent for root canal irrigation. Neem leaf extract is also used to treat dental plaque and gingivitis. Being a bio-compatible anti oxidant, use of neem is advantageous as it is not likely to cause the severe harms to patients that might occur through sodium hypochlorite accidents. Naiyak Arathi et al observed that ethanolic extract of neem had significant anti microbial activity against E.faecalis. [40] In another study by Hannah Rosaline et al, the effects of herbal extracts such as Morinda Citrifolia, Aadirachta indica and green tea were studied. The most to least effective irrigants were: Azadirchta indica, sodium hypochlorite, green tea, Morinda citrifolia and saline. Thus, it is an effective herbal alternative to the more commonly used irrigant sodium hypochlorite. [41]

\subsection{Aloe Vera (Aloe barbadensis miller):}

Aloe vera possesses good anti bacterial and anti fungal activity. In a study conducted by Suresh Chandra, anti microbial effect of water, alcohol, chloroform extracts of aloe vera gel were investigated and it was found that chloroform extract of aloe vera had significant anti microbial effect against E.faecalis. [42] It also has been found to be effective against the resistant micro organisms commonly found in the pulp.

\subsection{Morinda Citrifolia (noni):}

Morinda Citrifolia also known as Indian mulberry has a wide range of uses due to its biocompatibility, and anti bacterial, anti inflammatory, anti viral, anti oxidant and analgesic effects. It is one of the first herbal alternatives given for an intra canal irrigant. In a study conducted by Prabhakar AR et al, Morinda citrifolia was compared with Chlorhexidine as anti microbial endodontic irrigants. From this study, Morinda Citrifolia was found to have significant anti bacterial activity which is attributed due to its contents alizarin,scopoletin,aucubin and asperuloside. However it was lower than $0.2 \%$ Chlorhexidine. [43]

\subsection{Triphala and Green tea polyphenols:}

Triphala's fruit is rich in citric acid which helps in removing the smear layer. It's chelating property makes it an effective alternative to sodium hypochlorite for root canal irrigation. [44] Green tea polyphenols have significant anti oxidant, anti cariogenic, anti inflammatory, thermogenic, probiotic and anti microbial properties. [45] Triphala and Green tea polyphenols are preferred over the traditional root canals irrigants due to their curative properties such as anti oxidant, anti inflammatory and radical scavenging activities. In an in vitro study conducted by J.Prabhakar et al, Triphala and Green tea polyphenols were found to have significant anti microbial activity against E.faecalis biofilm formed in tooth substrate. [6] In another study by Madhu Pujar et al, antimicrobial efficiency of triphala, gren tea polyphenols and 3\% sodium hypochlorite were compared against and E.faecalis and it was observed that triphala and green tea polyphenols showed significantly better antibacterial activity against 2 week biofilm. [46]

\subsection{German chamomile and tea tree oil:}

German chamomile has anti inflammatory, analgesic and anti microbial properties. Tea tree oil also has many properties such as being an antiseptic, anti fungal agent, anti bacterial and a mild solvent. The active component in tea tree oil is terpinen-4-ol which is responsible for the above properties. [47] In a SEM study conducted to overcome the undesirable effects of sodium hypochlorite, it was observed that chamomile when 
used as an irrigant was more effective in removing smear layer when compared to sodium hypochlorite used alone but less effective than sodium hypochlorite combined with EDTA. [48] In another study by Uday Kamath et al, anti bacterial efficacy of tea tree oil was compared with $3 \%$ sodium hypochlorite and $2 \%$ Chlorhexidine against E.faecalis. It was found that maximum anti microbial activity was shown by Chlorhexidine followed by tea tree oil and then sodium hypochlorite. [49]

\subsection{Salvadora Persica Solution (Miswak-siwak):}

In a study conducted by Nawal A.K.Al-Sabawi et al, alcoholic extract of Salvadora Persica was compared with $5.25 \%$ sodium hypochlorite, $0.2 \%$ Chlorhexidine and normal saline. It was shown that Salvadora Persica extract had a significant anti microbial effect against both aerobic and anaerobic bacteria with its efficacy being maximum at $15 \%$. [50]

\subsection{Allium Sativum (Garlic):}

Its main active component is allicin which destroys the cell wall and cell membrane of root canal bacteria and thus can be used as an irrigant alternative to sodium hypochlorite. [51]

\subsection{Jeeryin Soution:}

This is a Chinese herbal compound with anti bacterial, anti inflammatory and detoxifying effects. When used at 30\% concentration for irrigation of root canal, it had a similar effect to that of sodium hypochlorite. [51]

\subsection{Myristica Fragrans (Nutmeg) and Terminalia Chebula:}

Myristica fragrans possesses anti bacterial property which is mainly due to its chief constituent myristic acid. Tannin is responsible for the anti bacterial action of terminalia Chebula. In a study conducted by Thila S.Vinothkumar et al, five different herbal extracts were evaluated as anti microbial endodontic irrigants. The efficiency of the extracts in descending order was as follows: Azadiracta Indica, Curcuma Longa, Myristica fragrans, Terminalia Chebula and Aloe Vera. [52]

\subsection{Aroeira-da-praia and Quixabeira:}

In an invitro study conducted by Edja Maria Melo de Brito Costa et al, anti microbial activity and root canal cleaning potential of Aroeira-da-praia and Quixabeira against E.faecalis was evaluated. It was concluded that Aroeira-da-praia showed anti microbial activity at all concentrations tested whereas Quixabeira was effective only at $100 \%$ and $50 \%$ concentrations. [53]

\subsection{Spilanthes Calva DC:}

Spilanthes Calva DC is an important herb for oral health care. It is non toxic to human beings and has anti bacterial and anti fungal activities. Moulshree Dube et al compared the anti bacterial efficacy of methanolic extract of Spilathes Calva DC roots with 2\% Chlorhexidine 3\% sodium hypochlorite and doxicycline at different concentrations against E.faecalis. From the study, it was concluded that Spilanthes Calva DC root extract had comparable anti bacterial activity to sodium hypochlorite. Thus it may have potential as a root canal irrigant. [54]

\subsection{Myrtus Communis:}

This plant has anti bacterial activity against both gram positive and gram negative organisms. In a study by Rajaa T Sulieman,the anti bacterial effect off Myrtus communis alcoholic extract solution when used as an intracanal irrigant was evaluated and compared with the currently used root canal irrigants. It was found that Myrus communis showed anti microbial effect at different dilutions, the best being at $35 \%$ concentration. Its effect was comparable to $5.25 \%$ sodium hypochlorite and $0.2 \%$ Chlorhexidine solution and showed nearly similar effect. [55]

\section{Conclusion}

The major advantages of herbal irrigants are safety, easy availability, increased shelf life, cost effectiveness and lack of microbial resistance so far. The in vitro studies conducted so far have shown that herbs can have a promising role as root canal irrigants. However, further clinical trials and investigations are required to be considered as effective alternatives to the synthetic root canal irrigants. 


\section{References}

[1]. Calt S, Serper A, Time dependent effects of EDTA on dentine structures, journal of endodontics, 28 (1), $2002,459-461$.

[2]. Hulsmann M, Heckendorff M, Lennon A, Chelating agents in root canal treatment: mode of action and indications for their use, Int Endodont J, 36, 2003, 810-830.

[3]. Sharad Kamat, Rajeev K, Prahlad Saraf., Role Of Herbs In Endodontics. An Update, Endodontology.

[4]. Zehnder M. Root canal irrigants, J Endod, 32, 2006, 389-98.

[5]. Peter E. Murray, Romi M. Farber, Kenneth N, Namerow et.al. Evaluation of Morinda citrifolia as an Endodontic Irrigant, J Endod, 34, 2008, 66-70.

[6]. J.Prabhakar, M.Senthikumar, M.S.Priya et.al, Evaluation of Antimicrobial Efficacy of Herbal Alternatives (Triphala and Green Tea Polyphenols), MTAD, and 5\% Sodium Hypochlorite against Enterococcus faecalis Biofilm Formed on Tooth Substrate: An In Vitro Study, J Endod, 36, 2010, 83-86.

[7]. Zahed Mohammadi, Yasd, Iran, Sodium Hypochlorite in Endodontics: an update review, IDJ, 58, $2008,329-41$.

[8]. F. Goldberg, A. Abramovich, Analysis of the effect of EDTAC on dentinal walls of the root canal, J Endod, 28,197 , p. 461.

[9]. M. Goldman, J.H. Kronman, L.B. Goldman, H. Clausen, J. New method of irrigation during endodontic treatment, J Endod, 2, 1976, p. 257.

[10]. I. Heling, N.P. Chandler, Antimicrobial effect of irrigant combinations within dentinal tubules, Int Endod J, 31, 1998, pp. 8-14.

[11]. Z.M. Kanisavaran, Chlorhexidine gluconate in endodontics: an update review, Int Dent J, 58, 2008, pp. $247-257$.

[12]. Yamashita JC, Tanomaru Filho M, Leonardo MR, Rossi MA, Silva LAB, Scanning electron microscope study of the cleaning ability of chlorhexidine as a root-canal irrigant, Int Endod J, 36, 2003, 391-4.

[13]. Yusof WZ, KhooSP, Mucosal sensitivity to chlorhexidine mouthwash, SingaporeDent J, 13, 1988, 39 - 40.

[14]. Meenu G. Singla, Ashima Garg, Sumit Gupta, MTAD in endodontics: an update review, Oral Surgery, Oral Medicine, Oral Pathology, Oral Radiology and Endodontology, 112 (3), 2011, 70-76.

[15]. Dilsah Cogulu, Atac Uzel, Kadriye Sorkun et.al, Efficacy of propolis as an intracanal medicament against Enterococcus faecalis, Gen Dent, 54, 2006, 319- 22.

[16]. Dobelis IN, ed, Magic and Medicine of Plants, Pleasantville, NY: Reader's Digest Association, Inc. 1986.

[17]. Mortellini R, Foresti R, Bassi R, Green CJ, Curcumin, an antioxidant and anti-inflammatory agent,induces heme oxygenase-1 and protects endothelial cells against oxidative stress., Free Radic Biol Med, 28, 2000, 1303-1312.

[18]. Apisariyakul A, Vanittanakom N, Buddhasukh D, Antifungal activity of turmeric oil extracted from Curcuma longa (Zingiberaceae), J Ethnopharmacol, 49, 1995, 163-169.

[19]. Kawamori T, Lubet R, Steele VE, et a, Chemopreventative effect of curcumin, a naturally occurring anti-inflammatory agent, during the promotion/progression stages of colon cancer, Cancer Rs, 59, 1999, 597-601.

[20]. Prasanna neelakantan, chandana subbarao, chandragiri venkata subbarao, analysis of antibacterial activity of curcumin against enterococcus fecalis, International journal of current research and review, 9, 2011.

[21]. Ikeno K, Ikeno T, Miyazawa C, Effect of Propolis on dental caries in rats, Caries Res, 25, 1991, 347-351.

[22]. Krol W, Czuba Z, Scheller S, Gabrys J, Grabiec S, Shani J, Antioxidant property of ethanolic extract of Propolis (EEP) as evaluated by inhibiting the chemilminescence oxidation of luminal, Biochem Int., 21, 1990, 593-597.

[23]. Borrelli F, Maffia P, Pinto L, Ianaro A, Russo A, Capasso F, Ialenti A, Phytochemical compounds involved in the antiinflammatory effect of propolis extract, Fitoterapia, 73, 2002, 53-63.

[24]. Sabir A, Tabbu CR, Agustiono P, Sosroseno W, Histological analysis of rat dental pulp tissue capped with propolis, J. Oral Sci., 47(3), 2005, 135-138.

[25]. Hayacibara MF, Koo H, Rosalen PL, Duarte S, Franco EM, Bowen WH, Ikegaki M, Cury JA, In vitro and in vivo effects of isolated fractions of Brazilian propolis on caries development, J. Ethnopharmacol., 101, 2005, 110-115.

[26]. Ozan F, Sümer Z, Polat ZA, Er K, Ozan U, De_er O, Effect of mouth rinse containing propolis on oral microorganisms and human gingival fibroblast, Eur. J. Dentistry, 11, 2007, 195-200.

[27]. Toker H, Ozan F, Ozer H, Ozdemir H, Eren K, Yeler HJ, A morphometic and histopathologic evaluation of the effects of Propolis on alveolar bone loss in experimental periodontitis in rats, Periodontol., 79(6), 2008, 1089-1094.

[28]. Al-Qathami H, Al-Madi E, Comparison of sodium hypochlorite, propolis and saline as root canal irrigants: A pilot study, Saudi Dental J., 5, 2003, 100-102.

[29]. Khan R, Antimicrobial Activity of Five Herbal Extracts Against Multi Drug Resistant (MDR) Strains of Bacteria and Fungus of Clinical Origin, Molecules., 14(2), 2009, 586-597.

[30]. Duganath N, Evaluation of antidenaturation property and anti-oxidant activity of traditionally used medicinal plants, Int. J. Pharma. Bio Sciences., 1(2), 2010, 1-7.

[31]. Satish S, Mohana D.C. and Raghvendra M.P, Antifungal activity of some plant extracts against important seed borne pathogens of Aspergillus sp, J. Agri. Tech, 3(1), 2007, 109-119.

[32]. Mohamed L.T., Bushra E.I.S and Abdelrahman M.N, The antibacterial, antiviral activities and phytochemical screening of some Sudanese medicinal plants, Eur. Asian. J.BioSciences, 4, 2010, 8-16.

[33]. Shanab S.M.M, Antioxidant and Antibiotic Activities of Some Seaweeds (Egyptian Isolates), Int. J. Agri. Biol., 9(2), 2007, 220225.

[34]. Rosina Khan, Barira Islam, Mohd Akram, Shazi Shakil, Anis Ahmad ,S. Manazir Ali , Antimicrobial Activity of Five Herbal Extracts Against Multi Drug Resistant (MDR) Strains of Bacteria and Fungus of Clinical Origin, Molecules, 14, $2009,586-597$.

[35]. Dhanya Kumar et al, The Antimicrobial Activity Of Azardirachta Indica, Glycyrrhiza Glabra, Cinnamum Zeylanicum, Syzygium Aromaticum, Accacia Nilotica On Streptococcus Mutans And Enterococcus Faecalis - An In Vitro Study, Endodontology journal, available at http://medind.nic.in/eaa/t11/i1/eaat11i1p16.pdf

[36]. Rao, A. R., Kumar, S., Paramsivam, T. B., Kamalakshi, S., Parashuram, A. R. And Shantha, M., Indian J. Med. Res., 57, 1969, 495-502.

[37]. Khan, M. and Wassilew, S. W., in Natural Pesticides from the Neem Tree and Other Tropical Plants (eds Schmutterer, H. And Asher, K. R. S.), GTZ, Eschborn, Germany, 1987, pp. 645-650.

[38]. Balasenthil, S., Arivazhagan, S., Ramachandran, C. R. and Nagini, S., J. Ethnopharmacol., 67, 1999, 189-195.

[39]. Chopra, I. C., Gupta, K. C. and Nair, B. N., Indian J. Med. Res., 40, 1952, 511- 515.

[40]. Naiyak Arathi et al, Evaluation of Antibacterial and Anti candidial efficacy of Aqueous and Alcoholic extract of Neem (Azadhiracta indica)-An In Vitro study, International Journal of Research in Ayurveda \& Pharmacy, 2(1), 2011, $230-235$.

[41]. Hannah Rosaline, Kandaswamy D, Gogulnath D, Rubin MI, Influence of various herbal irrigants as a final rinse on the adherence of Enterococcus faecalis by fluorescence confocal laser scanning microscope, Journal of Conservative Dentistry, 16 (4), July-Aug 2013, 352-355. 
[42]. B. Sureshchandra And Arun J. Kumar, in vitro antibacterial efficacy of Aloevera extract on Resistant antimicrobial strains in endodontics, .available at Http://Medind.Nic.In/Eaa/T11/I1/Eaat11i1p56.Pdf

[43]. AR Prabhakar, Priyanka Basavraj, N Basappa, Comparative evaluation of Morinda citrifolia with Chlorhexidine as antimicrobial endodontic irrigants and their effect on micro-hardness of root canal dentin: an in vitro study, International journal of Oral Health Sciences, 3(1), jan-jun 2013, 5-8.

[44]. Prabhakar J, Senthil kumar M, Priya M S, Mahalakshmi K, Sehgal PK, Sukumaran VG, Evaluation of antimicrobial efficacy of herbal alternatives (Triphala and Green tea polyphenols),MTAD and 5\% sodium hypochloride against Enterococcus faecalis biofilm formed on tooth substrate: An invitro study, J Endod, 36, 2010, 83-86.

[45]. Pulok K. Mukherjee, Sujay Rai, Sauvik Bhattacharyya et.al, Clinical study of 'Triphala'- A Well Known Phytomedicine from India, IJPT, 5, 2006, 51-4.

[46]. Madhu Pujar, Chetan Patil and Ajay Kadam, Comparison of antimicrobial efficacy of Triphala, (GTP) Green tea polyphenols and $3 \%$ of sodium hypochlorite on Enterococcus faecalis biofilms formed on tooth substrate: in vitro, Journal of International Oral Health, 3(2), 2011, 23-30.

[47]. Milind Parle, Nitin Bansal, Herbal medicines: Are they safe? , Natural Product Radiance,5, $2006,6-14$.

[48]. M.S. Sadr Lahijani, H.R. Raoof Kateb, R. Heady et.al, The effect of German chamomile (Marticaria recutitia L.) extract and tea tree( Melaleuca alternifolia L.) oil used as irrigants on removal of smear layer: a scanning electron microscopy study., Int Endod J, 39, 2006, 190-95.

[49]. Uday Kamath, Hina Sheth, Sai Ramesh, Keshav Singla, Comparison of the antibacterial efficacy of tea tree oil with 3\% sodium hypochlorite and 2\% Chlorhexidine against E.faecalis: An in vitro study., Journal of Contemporary Dentistry, 3(3), 2013, 117-120.

[50]. Al- subawi NAK, Abdull- khalik K,Mahmud Y, Taha MY, Abdul A, The Antimicrobial actitvity ion of Salvadora persica solution (Miswak -siwak) as root canal irrigant, University of sharjah journal of pure \& applied science, 4, 2007, 69-91.

[51]. Traditional Chinese medicine used in root canal disinfection research. Pharmacy papers (Online article). http://eng.hi138.com/?b106.

[52]. Thilla S Vinothkumar, Mohamed I Rubin, Lakshmi Balaji, Deivanayagam Kandaswamy, In vitro evaluation of five different herbal extracts as an antimicrobial endodontic irrigant using real time quantitative polymerase chain reaction, Journal of Conservative Dentistry, 16(2), 2013, 167-170.

[53]. Edja Maria Melo de Brito Costa et al., In vitro evaluation of the root canal cleaning ability of plant extracts and their antimicrobial action, Braz Oral Res, 26(3), 2012, 215-21.

[54]. Moulshree Dube et al, Comparative evaluation of antibacterial efficacy of spilanthes calva DC root extract, sodium hypochlorite, Chlorhexidine and doxycycline at different concentrations on enterococcus faecalis- An in-vitro study, Endodontology, 25(1), 2013, 63-72.

[55]. Suliman RT, The Antibacterial Effect of Myrtus communis as Root Canal Irrigant: A comparative Study, Al-Rafidain Dent J, 9 (2), 2009, 289-296. 